\title{
The Effect of Applying Global Positioning System in Ambulances on Response Time of Tehran Emergency Medical Service
}

\author{
Vahid Delshad ${ }^{1}$, Hashem Shemshadi², Mohammad Javad Moradian³, Shokoufeh Ahmadi', Lila Malkyan", Samaneh Sabzalizadeh ${ }^{5}$ \\ 1. Department of Health in Emergency and Disaster Research Center, University of Social Welfare and Rehabilitation Sciences, Tehran, Iran. \\ 2. Department of Clinical Sciences, University of Social Welfare and Rehabilitation Sciences, Tehran, Iran. \\ 3. Department of Disaster in Emergency, School of Public Health, Tehran University of Medical Sciences, Tehran, Iran. \\ 4. Department of Nursing, Faculty of Nursing and Midwifery, Bam University of Medical Sciences, Bam, Iran. \\ 5. Health Technology Office, Vice Chancellor for Research \& Technology, Univereity of Social Welfare and Rehabilitation Sciences, Tehran, Iran
}

Citation: Delshad V, Shemshadi H, Moradian MJ, Ahmadi Sh, Malkyan L, Sabzalizadeh S. The effect of applying global positioning system in ambulances on response time of Tehran emergency medical service. Health in Emergencies and Disasters Quarterly. 2016; 1(3): 125-128. http://doi.org/10.15412/j.hdq.09010302

dol: : http://doi.org/10.15412/j.hdq.09010302

\section{Article info:}

Received: 25 Nov. 2015

Accepted: 14 Feb. 2016

\section{Keywords:}

Prehospital, Emergency medical service, Global positioning system, Ambulance, Response time, Tehran

\begin{abstract}
Background: Identification of the effective factors in reducing response time in prehospital emergency medical service (EMS) can assist in improving its services. This study aimed at reviewing the effect of applying global positioning system (GPS) on response time of Tehran EMS ambulances.

Materials and Methods: Of 132 Tehran EMS stations, 24 ones were randomly selected, and relevant data, including the response time of all missions in 2009 (without GPS) and in 2011 (with GPS) as well as number of daily calls to each dispatch center were extracted. The average number of daily calls in the call centers were categorized into 3 groups as follows: I) $\leq 10$ calls, II) 10 to 15 calls, and III) $>15$ calls. The statistical analysis of the obtained data was carried out by paired $t$ test.
\end{abstract}

Results: The findings revealed that the average response times in 2009 for the 3 groups (I, II, and III) were 10.11, 11.25, and 10.92 minutes, respectively. These times recorded for groups (I, II, and III) in 2011 were $9.86,10.71$, and 11.58 minutes, respectively, which were significantly less than the response times recorded in $2009(\mathrm{P}<0.001)$.

Conclusion: This research has demonstrated that the application of GPS in the ambulances may be essential in the reduction of response time, especially in emergency stations with more average mission numbers.

\section{* Corresponding Author:}

Samaneh Sabzalizadeh, MS

Address: Health Technology Office, Vice Chancellor for Research \& Technology, Univereity of Social Welfare and Rehabilitation Sciences, Kodakyar Ave., Daneshjoo Blvd., Evin, Tehran, Iran.

E-mail: alizade.samaneh@gmail.com 


\section{Introduction}

$\mathbf{I}$

n Iran, prehospital emergency medical system (EMS), a subdivision of center for disaster management and emergency medicine, is an important part of the health system [1]. Prehospital EMS plays a vital role in the network of health system by transferring patient to the nearest hospital [2]. The prehospital EMS aims at provision of proper treatment in the appropriate place and time by deploying the available resources [3]. Its services begin with the basic treatment and medical care and end in the emergency department of the hospital $[4,5]$.

The main task of EMS is to handle emergency medical cases, which if not dealt with on time, would result in irreversible physical and mental injuries for patients. For example, every year, over 50 million people are injured worldwide and 2.1 million are killed in traffic accidents [6]. Additionally, cardiac arrest is one of the most prevalent cause of fatality in the world [7], claiming nearly 17 million lives. Of them, more than $50 \%$ die due to cardiac and respiratory arrest in the absence of resuscitation which can done by prehospital EMS [8]. The rate of successful cardiopulmonary resuscitation in the finest emergency management worldwide ranges from $5 \%$ to $10 \%$ [9]. However, in Iran, reports have shown an average of $5 \%$ to $7 \%$, owing to EMS response time [10].

A novel means of interaction between ambulance services and computer-aided dispatch (CAD) is global positioning system (GPS) [11]. It is one of the most important and reliable systems in showing location at any time and reporting it to $\mathrm{CAD}$ for use, analysis, and display of the results on the map [12]. Effected from May 2010, all ambulances of Tehran Emergency 115 (EMS) were equipped with GPS, and their information is reported via satellite to CAD. Providing ambulances with GPS can result in saving time, reducing the possibility of emergency medical technicians' (EMT) offenses, and accurately monitoring the function of ambulances [13].

Some studies proved the positive influence of GPS on the ambulance response time $[14,15]$. The present study compared the average response time of ambulances in 2009 (when ambulances were not equipped with GPS) with that time in 2011 (when ambulances were equipped with GPS), to investigate the causal relation between the effect of GPS and the reduction of ambulance response time.

\section{Materials and Methods}

This survey is a retrospective descriptive study, aimed at comparing the average time of ambulance response in
2009 (without GPS) with that time in 2011 (with GPS). Considering the 132 EMS stations in Tehran, 24 stations were randomly selected for the study. The average time between ambulance scene arrival time (SAT) and start mission time (SMT) and the number of daily calls to each emergency dispatch centers in 2009 and 2011 were collected from Tehran emergency information and communication center.

With regard to Tehran emergency system, response time was calculated from the moment of mission report to $\mathrm{CAD}$ to the moment of ambulance dispatch plus the time from the moment of ambulance dispatch to the moment of ambulance presence at the scene (both times were recorded by technicians of $\mathrm{CAD}$ via wireless phone). By converting the data time of 10-96 (measured in seconds) to minute, coupled with the data time of 10 97, the average time of ambulance response according to the number of calls was calculated for each center. These centers were categorized into 3 groups: I) $\leq 10$ calls, II) 10 to 15 calls, and III) $>15$ calls. The data were analyzed by paired $t$ test using SPSS version 16 . The statistical significance of the results was set at $\alpha=0.05$.

\section{Results}

Table 1 shows the comparison of response time measured in minutes for 24 emergency centers in the year 2009 and 2011. By comparing records obtained in 2009 with that of 2011, it was found that the response time in group I (10 or fewer calls) significantly increased from 11.25 to 11.58 minutes $(\mathrm{P}<0.001)$.

By comparing years 2009 and 2011 for the group II (10 to 15 calls), the average time of ambulance response significantly decreased from 10.92 to 10.71 minutes $(\mathrm{P}<0.001)$. The comparison between year 2009 and 2011 for the third group (more than 15 calls) showed that the average time of ambulance response significantly decreased from 10.11 to 9.86 minutes $(\mathrm{P}<0.001)$.

\section{Discussion}

Response time is a key factor in the reduction of irreversible injuries in accidents and using new technologies can be considerably effective. Our study results agree with the study of Ota (2000), in which the use of GPS and display map in ambulances can effectively reduce both the response time and the distance travelled [15]. The GPS system employed in Tehran prehospital emergency is only used in the monitoring of ambulance services, while other facilities of GPS such as the guiding system for showing the nearest and most appropriate 
Table 1. The comparison of response times measured in minutes.

\begin{tabular}{|c|c|c|c|c|c|}
\hline \multirow{2}{*}{ Groups } & \multirow{2}{*}{ Year } & \multicolumn{2}{|c|}{ Response time, $\min$} & \multirow{2}{*}{$\mathbf{T}$} & \multirow{2}{*}{ Sig. (2-tailed) } \\
\hline & & Mean & SD & & \\
\hline \multirow{2}{*}{ Group 1} & 2011 & 11.5842 & 3.86980 & \multirow{2}{*}{3.700} & \multirow{2}{*}{0.001} \\
\hline & 2009 & 11.2571 & 3.05111 & & \\
\hline \multirow{2}{*}{ Group 2} & 2011 & 10.7117 & 2.98899 & \multirow{2}{*}{-3.474} & \multirow{2}{*}{0.001} \\
\hline & 2009 & 10.9240 & 2.70925 & & \\
\hline \multirow{2}{*}{ Group 3} & 2011 & 9.8649 & 2.15705 & \multirow{2}{*}{-4.199} & \multirow{2}{*}{0.000} \\
\hline & 2009 & 10.1153 & 2.29002 & & \\
\hline
\end{tabular}

pathway (street) for reaching the event location, can result in the reduction of response time and other expenses in health services, and hence improving the quality of EMS.

In line with our findings, Pelege and his colleagues indicated that the exploitation of geographic information system (GIS) for making models of the ambulance location can reduce response time; however, such projects demand many infrastructures. Additionally, Gonzalez reported that the involvement of GPS in suburban missions can positively affect the response time [14]. Contrary to heavy traffic and long distances in cities, missions in suburban areas experience much lighter traffic; hence, focusing on distances in suburban missions seems logical.

In Tehran emergency services, each emergency center contains a defined territory. In emergency situations, adjacent centers act beyond their defined territories by travelling longer distances, leading to increase in the response time. This problem is also evident in the present study, where the use of GPS is more effective when the number of missions is more than 10. Possibly, before the installation of GPS, technicians may have reported an earlier time of dispatch rather than the real time; the issue which may have been reduced owning to the fear of proceeding controls after the GPS installation. Therefore, the significant reduction of response time in this study may be due to the use of GPS, or reduction in the number of spurious reports of dispatch time. This issue can be investigated in subsequent studies.

One of the study limitations was the inability of the research team to design suitable criteria for considering traffic load and volume in data analysis. This shortcoming can be obviated in subsequent studies. Other weaknesses include overwhelming larger city populations (different distances of technician's location from ambulance, and the differences in the possession of 1 ambulance in an emergency center and 2 ambulances in another center).

\section{Conclusion}

This research has demonstrated that application of GPS in the ambulances may be essential in the reduction of response time, especially in emergency stations with more average mission numbers. GPS in Iran is only used for monitoring and supervising locations of ambulances and the use of other services such as road map to show the closest route with lighter traffic, and identifying closest ambulance to the scene is beneficial. Therefore, using GPS in EMS is highly recommended.

\section{Acknowledgements}

We sincerely thank Dr. Fuladi, the emergency manager, staffs of Tehran Emergency Medical Service, University of Socioal Welfare and Rehabilitation Sciences and Rofideh Rehabilitation Hospital. Moreover, we offer our gratitude to Mahdi Bahmanabadi for his invaluable efforts in gathering data.

\section{Conflict of Interests}

The authors declared no conflict of interests.

\section{References}

[1] Roudsari BS, Nathens AB, Arreola-Risa C, Cameron P, Civil I, Grigoriou G, Gruen RL, et al. Emergency medical service (EMS) systems in developed and developing countries. Injury. 2007; 38(9):1001-013.

[2] Morrison LJ, Verbeek PR, McDonald AC, Sawadsky BV, Cook DJ. Mortality and prehospital thrombolysis for acute 
myocardial infarction. Journal of the American Medical Association. 2000; 283(20):2686-692.

[3] Allison K, Porter K. Consensus on the prehospital approach to burns patient management. Accident and Emergency Nursing. 2004; 12(1):53-57.

[4] Khashayar P, Amoli HA, Tavakoli H, Panahi F. Efficacy of pre-hospital care in trauma patients in Iran. Emergency Medicine Journal. 2010; 27(6):430-32.

[5] Carpenter CR, Shah MN, Hustey FM, Heard K, Gerson LW, Miller DK. High yield research opportunities in geriatric emergency medicine: prehospital care, delirium, adverse drug events, and falls. Journals of Gerontology Series A: Biological Sciences and Medical Sciences. 2011; 66(7):775-83.

[6] Bulman RJ, Wortman CB. Attributions of blame and coping in the "real world": severe accident victims react to their lot. Journal of Personality and Social Psychology. 1977; 35(5):35163.

[7] Mozaffarian D, Benjamin EJ, Go AS, Arnett DK, Blaha MJ, Cushman $\mathrm{M}$, et al. Executive summary: heart disease and stroke statistics-2016 Update: a report from the American Heart Association. Circulation. 2016; 133(4):447-54. doi 10.1161/CIR.0000000000000366

[8] Neukamm J, Gräsner JT, Schewe JC, Breil M, Bahr J, Heister $\mathrm{U}$, et al. The impact of response time reliability on CPR incidence and resuscitation success: a benchmark study from the German Resuscitation Registry. Critical Care. 2011; 15(6):1-15.

[9] Goodarzi A, Jalali A, Almasi A, Naderipour A, Kalhori RP, Khodadadi A. Study of survival rate after cardiopulmonary resuscitation (CPR) in hospitals of Kermanshah in 2013. Global Journal of Health Science. 2015; 7(1):52.

[10] Hassani SA, Moharari RS, Sarvar M, Nejati A, Khashayar $P$. Helicopter emergency medical service in Tehran, Iran: a descriptive study. Air Medical Journal. 2012; 31(6):294-97. doi 10.1016/j.amj.2012.05.001

[11] Hummel RS, Clarke AM, Gervin AS. Global positioning system. New directions in ground/air communications. Journal of Emergency Medical Services. 1993; 18(10):63-64.

[12] Ota FS, Muramatsu RS, Yoshida BH, Yamamoto LG. GPS computer navigators to shorten EMS response and transport times. American Journal of Emergency Medicine. 2001; 19(3):204-05.

[13] Gonzalez RP, Cummings GR, Mulekar MS, Harlan SM, Rodning CB. Improving rural emergency medical service response time with global positioning system navigation. 2009; 67(5):899-902. doi: 10.1097/TA.0b013e3181bc781d

[14] Wadhe P, Pandharkar R, Raut R, Modi D. Emergency Service using GPS Tracking. International Journal of Advanced Research in Computer and Communication Engineering. 2016; 5(4):534-537.

[15] Peleg K, Pliskin JS. A geographic information system simulation model of EMS: reducing ambulance response time. American Journal of Emergency Medicine. 2004; 22(3):164-70. 